\title{
FIVE YEARS LIDAR RESEARCH ON BOARD THE FACILITY FOR AIRBORNE ATMOSPHERIC MEASUREMENTS (FAAM)
}

Franco Marenco

\author{
Met Office, Observations Based Research, Exeter EX1 3PB, United Kingdom.
}

Email:franco.marenco@metoffice.gov.uk

\begin{abstract}
I will present a summary of the results obtained with the backscatter lidar on-board the FAAM research aircraft. This simple instrument has been used in several campaigns, and has contributed successfully to the characterization of volcanic ash, mineral dust, biomass burning aerosols, clouds, and the boundary layer structure. Its datasets have been used in many applications, from numerical weather predictions to the validation of satellite remote sensing.
\end{abstract}

\section{INTRODUCTION}

The Facility for Airborne Atmospheric Measurements (FAAM) BAe-146 research aircraft (www.faam.ac.uk) is a major asset for the British scientific community. Its purpose is to provide independent observations of atmospheric fields and to permit simultaneous and complementary observations from a range of in situ and remote sensing instruments. The flying programme is primarily aimed at improving the Met Office weather prediction model and its parametrisations, and to verify/validate satellite retrievals. The aircraft may also be occasionally used operationally, e.g. to face civil contingencies.

The aircraft is equipped with a simple ALS450 backscatter lidar manufactured by Leosphere, operating at $355 \mathrm{~nm}$ and pointing at nadir. The success of this simple instrument relies on several factors: (1) it is complemented by full suite of measurements on board FAAM, which provide in situ and passive remote sensing information; (2) the campaigns of the FAAM aircraft are supported by multi-disciplinary teams capable of exploiting the data for a wide spectrum of scientific objectives; and (3) the instrument's ease of operation and relative robustness allow intensive use for campaigns in different parts of the world, targeting different objectives. In this presentation
I shall present some of the major applications of the instrument.

\section{AEROSOL APPLICATIONS}

The airborne lidar has been extensively used for aerosol measurements, and its data have been combined with in situ measurements obtained by nephelometer and optical particle counters.

In 2010, the lidar provided a detailed dataset of spatially-resolved volcanic ash concentrations [1]. Thanks to the on-board in situ optical particle counters and to passive remote sensing with the ARIES infrared spectrometer, a closure of the observations has been possible [2,3].

In 2011 and 2012 the aircraft has taken part in the Fennec experiment, targeted at studying the meteorology of the Saharan Heat Low region [4]. The lidar measurements have been very successful at mapping the turbulent structure of the Saharan atmospheric boundary layer[5].

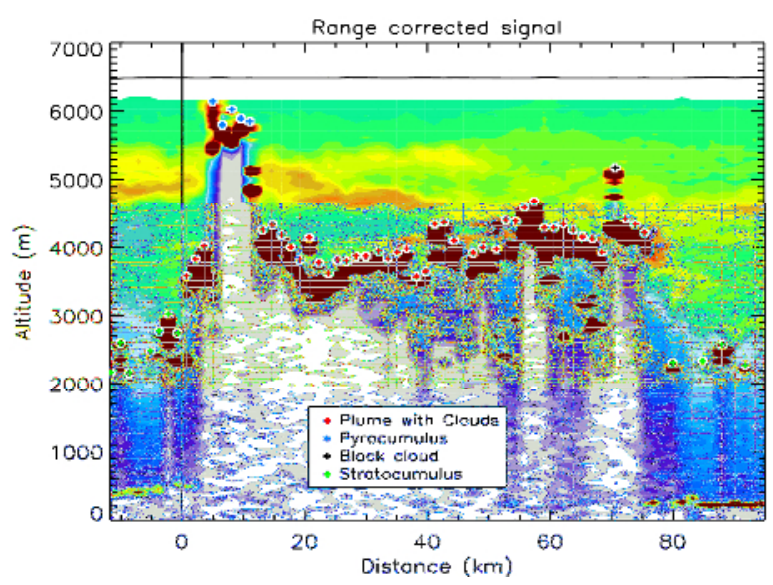

Figure 1. Mapping single-fire smoke plumes by lidar in the Amazon. 
Later in 2012, a major aerosol campaign has been the South American Biomass Burning Analysis (SAMMBA). Aerosols in the Brazilian rainforest have been extensively studied during the biomass burning season using ground-based [6] and airborne measurements. The airborne lidar has produced the detailed mapping of the regional haze and a thorough analysis of its vertical distribution. The geometry of single fire plumes has also been studied (see Fig. 1).

\section{CLOUD APPLICATIONS}

The airborne lidar has been used in research flights around the United Kingdom, targeting the properties of cirrus. Here, the lidar quantitative measurements, together with other observations, helped validating a microphysical model of the cloud properties, capable of predicting the scattering properties across the electromagnetic spectrum from UV to radar frequencies (see Fig. 2 and Ref. [7]) and the relationship between the phase function and the atmospheric state [8].

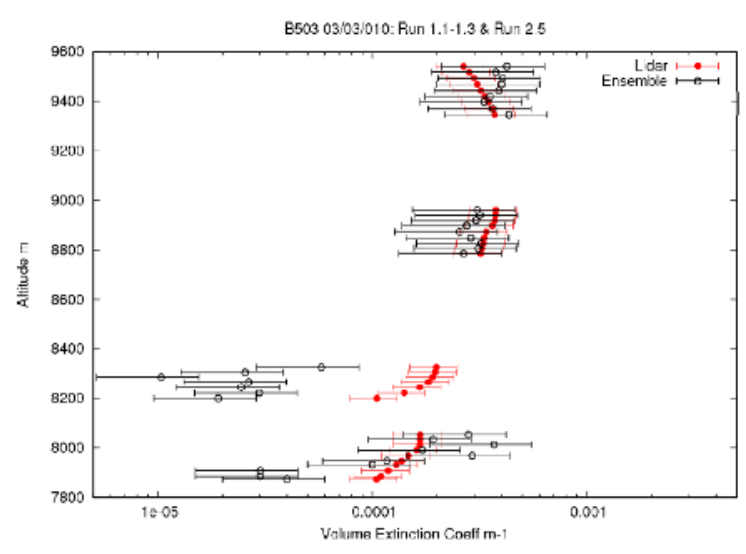

Figure 2. Cirrus extinction coefficient profile, determined by lidar (red) and a microphysical model (black).

A simple threshold-based approach to cloud detection and the measurement of cloud top height has been established [9]. It has enabled the mapping of the evolution of stratus and stratocumulus, when advected over land. It has been successfully exploited in a comprehensive study, aimed at understanding the strengths and weaknesses of the Met Office numerical weather prediction model [10].

For a study on cloud cover over the Sahara desert, the lidar cloud-detection algorithm has been reinforced using co-located broadband passive infrared measurements, yielding a robust product. Along-track cloud maps at $\sim 300 \mathrm{~m}$ resolution have been established during 25 research flights (see Fig. 3), with the purpose of verifying model predictions and Meteosat observations (analysis is ongoing).

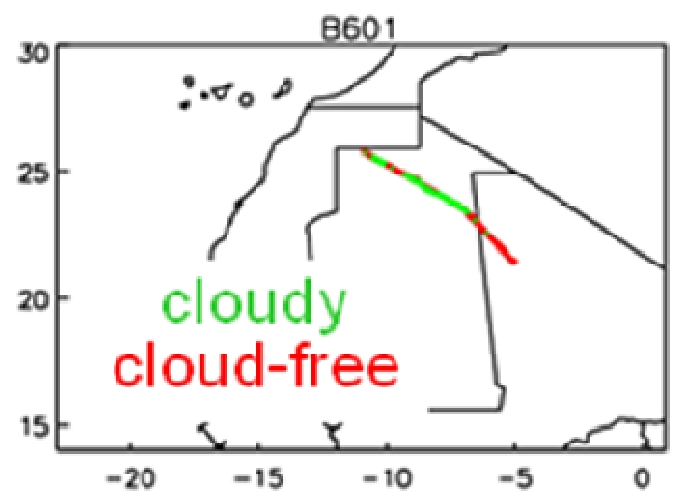

Figure 3. Cloud map in the Sahara, established by lidar and infrared radiometer.

\section{THE ICE-D CAMPAIGN}

In August 2015, the FAAM aircraft will be detached to Cape Verde to take part in the ICE-D campaign. The campaign objectives are focused on the ice nucleation properties of mineral dust, aerosol mapping for the assessment of dust predictions, and the verification of dust remote sensing with Meteosat and CALIPSO.

Two additional components of the campaign will be the validation of aerosol ground-based remote sensing retrievals (pending funding application). The SAVEX-D component will assess the retrievals of size-distribution, single-scattering albedo, and refractive index obtained from AERONET and SKYRAD sunphotometer retrievals. The ACCURATE component will the evaluation of the GARRLiC algorithm using multi-wavelength Raman lidar and AERONET [11]. 


\section{ACKNOWLEDGEMENTS}

Airborne data was obtained using the BAe-146 Atmospheric Research Aircraft flown by Directflight Ltd. and managed by the Facility for Airborne Atmospheric Measurements (FAAM), which a joint entity of the Natural Environment Research Council (NERC) and the Met Office. Fennec was funded by NERC (grant NE/G017166/). SAMBBA was funded by the Met Office and NERC (grant NE/J009822/1). This research has been carried partly at the University of Leeds, within the framework of the Met Office Academic Partnership scheme.

\section{REFERENCES}

[1] Marenco et al, Airborne lidar observations of the 2010 Eyjafjallajökull volcanic ash plume, J. Geophys. Res. 116, 10.1029/2011JD016396, 2011.

[2] Turnbull et al, A case study of observations of volcanic ash from the Eyjafjallajökull eruption: 1. In situ airborne observation, J. Geophys. Res. 117, 10.1029/2011JD016688, 2012.

[3] Newman et al, A case study of observations of volcanic ash from the Eyjafjallajökull eruption: 2. Airborne and satellite radiative measurements, J. Geophys. Res. 117, 10.1029/2011JD016780, 2012.

[4] Ryder et al, Advances in understanding mineral dust and boundary layer processes over the Sahara from Fennec aircraft observations, Atmos. Chem. Phys. Discuss. 15, 199-290, 2015.

[5] Garcia-Carreras et al, Turbulent structure and diurnal growth of the Saharan atmospheric boundary layer, J. Atmos. Sci., 10.1175/JAS-D13-0384.1, 2014.

[6] Brito et al, Ground-based aerosol characterization during the South American Biomass Burning Analysis (SAMBBA) field experiment, Atmos. Chem. Phys. 14, 1206912083, 2014.

[7] Baran et al, A self-consistent scattering model for cirrus. II: The high- and low-frequencies, Q. J. Roy. Met. Soc. 140, 1039-1057, 2014.
[8] Baran et al, On the relationship between the scattering phase function of cirrus and the atmospheric state, Atmos. Chem. Phys. 15, 11051127, 2015.

[9] Allen et al, Atmospheric composition and thermodynamic retrievals from the ARIES airborne TIR-FTS system -- Part 2: Validation and results from aircraft campaigns, Atmos. Meas. Tech. 7, 4401-4416, 2014.

[10] Osborne et al, Evolution of stratocumulus over land: comparison of ground and aircraft observations with numerical weather prediction simulations, Bound. Lay Meteorol. 153, 165-193, 2014.

[11] Wagner et al, Evaluation of the Lidar/Radiometer Inversion Code (LIRIC) to determine microphysical properties of volcanic and desert dust, Atmos. Meas. Tech. 6, 17071724, 2013. 